\title{
IS GENE THERAPY A FORM OF EUGENICS?
}

\section{JOHN HARRIS}

Eugenic A. adj. Pertaining or adapted to the production of fine offspring. B. sh. in pl. The science which treats of this. (The Shorter Oxford English Dictionary Third Edition 1965).

It has now become a serious necessity to better the breed of the human race. The average citizen is too base for the everyday work of modern civilization. Civilised man has become possessed of vaster powers than in old times for good or ill but has made no corresponding advance in wits and goodness to enable him to conduct his conduct rightly, (Sir Francis Galton)

If, as I believe, gene therapy is in principle ethically sound except for its possible connection with eugenics then there are two obvious ways of giving a simple and straightforward answer to a question such as this. The first is to say "yes it is, and so what?" The second is to say "no it isn't so we shouldn't worry". If we accept the first of the above definitions we might well be inclined to give the first of our two answers. If on the other hand, we accept the sort of gloss that Ruth Chadwick gives on Galton's account, "those who are genetically weak should simply be discouraged from reproducing", either by incentives or compulsory measures, we get a somewhat different flavour, and one which might incline a decent person who favours gene therapy towards the second answer.

The nub of the problem turns on how we are to understand the objective of producing "fine children". Does "fine" mean "as fine as children normally are", or does it mean "as fine as a child can be"? Sorting out the ethics of the connection between gene therapy and eugenics seems to involve the resolution of two morally significant issues. The first is whether or not there is a relevant moral distinction between attempts to remove or repair dysfunction on the one hand and measures designed to enhance function on the other, such that it would be coherent to be in favour of curing dysfunction but 
against enhancing function? The second involves the question of whether gene therapy as a technique involves something specially morally problematic.

\section{THE MORAL CONTINUUM}

Is it morally wrong to wish and hope for a fine baby girl or boy? Is it wrong to wish and hope that one's child will not be born disabled? I assume that my feeling that such hopes and wishes are not wrong is shared by every sane decent person. Now consider whether it would be wrong to wish and hope for the reverse? What would we think of someone who hoped and wished that their child would be born with disability? Again I need not spell out the answer to these questions.

But now let's bridge the gap between thought and action, between hopes and wishes and their fulfilment. What would we think of someone who, hoping and wishing for a fine healthy child, declined to take the steps necessary to secure this outcome when such steps were open to them?

Again I assume that unless those steps could be shown to be morally unacceptable our conclusions would be the same.

Consider the normal practice at I.V.F. clinics where a woman who has had say, five eggs fertilised in vitro, wishes to use some of these embryos to become pregnant. Normal practice would be to insert two embryos or at most three. If pre-implantation screening had revealed two of the embryos to possess disabilities of one sort or another, would it be right to implant the two embryos with disability rather than the others? Would it be right to choose the implantation embryos randomly? Could it be defensible for a doctor to override the wishes of the mother and implant the disabled embryos rather than the healthy ones - would we applaud her for so doing?'

The answer that I expect to all these rhetorical questions will be obvious. It depends however on accepting that disability is somehow disabling and therefore undesirable. If it were not, there would be no motive to try to cure or obviate disability in health care more generally. If we believe that medical science should try to cure disability where possible, and that parents would be wrong to withhold from their disabled children cures as they become available, then we will be likely to agree on our answers to the rhetorical questions posed.

1 The argument here follows that of my paper "Should We Attempt to Eradicate Disability" to be published in the Proceedings of the Fifteenth International Wittgenstein Symposium.

(C) Basil Blackwell Lid 1993 


\section{WHAT IS DISABILITY?}

It is notoriously hard to give a satisfactory definition of disability although I believe we all know pretty clearly what we mean by it. A disability is surely a physical or mental condition we have a strong rational preference not to be in, it is, more importantly, a condition which is in some sense a 'harmed condition'. ${ }^{2}$ I have in mind the sort of condition in which if a patient presented with it unconscious in the casualty department of a hospital and the condition could be easily and immediately reversed, but not reversed unless the doctor acts without delay, a doctor would be negligent were she not to attempt reversal. Or, one which, if a pregnant mother knew that it affected her fetus and knew also she could remove the condition by simple dietary adjustment, then to fail to do so would be to knowingly harm her child. ${ }^{3}$

To make clearer what's at issue here let's imagine that as a result of industrial effluent someone had contracted a condition that she felt had disabled or harmed her in some sense. How might she convince a court say, that she had suffered disability or injury?

The answer is obvious but necessarily vague. Whatever it would be plausible to say in answer to such a question is what I mean (and what is clearly meant) by disability and injury. It is not possible to stipulate exhaustively what would strike us as plausible here, but we know what injury is and we know what disability or incapacity is. If the condition in question was one which set premature limits on their lifespan - made their life shorter than it would be with treatment, or was one which rendered her specially vulnerable to infection, more vulnerable than others, we would surely recognise that she had been harmed and perhaps to some extent disabled. At the very least such events would be plausible candidates for the description "injuries" or "disabilities".

Against a background in which many people are standardly protected from birth or before against pollution hazards and infections and have their healthy life expectancy extended, it would surely be plausible to claim that failure to protect in this way constituted an injury and left them disabled. Because of their vulnerability to infection and to environmental pollutants there would be places it was unsafe for them to go and people with whom they could not freely consort. These restrictions on liberty are surely at least prima facie disabling as is the increased relative vulnerability.

\footnotetext{
${ }^{2}$ See my discussion of the difference between harming and wronging in my Wonderwoman E' Superman: The Ethics of Human Biotechnology. Oxford, 1992. Chapter 4.

${ }^{3}$ This goes for relatively minor conditions like the loss of a finger or deafness and also for disfiguring conditions right through to major disability like paraplegia.
} 
These points are crucial because it is sometimes said that while we have an obligation to cure disease - to restore normal functioning - we do not have an obligation to enhance or improve upon a normal healthy life, that enhancing function is permissive but could not be regarded as obligatory. But, what constitutes a normal healthy life, is determined in part by technological and medical and other advances (hygiene, sanitation etc.) It is normal now for example to be protected against tetanus, the continued provision of such protection is not merely permissive. If the AIDS pandemic continues unabated and the only prospect, or the best prospect, for stemming it's advance is the use of gene therapy to insert genes coding for antibodies to AIDS, I cannot think that it would be coherent to regard making available such therapy as permissive rather than mandatory. ${ }^{4}$

If this seems still too like normal therapy to be convincing, suppose genes coding for repair enzymes which would not only repair radiation damage or damage by other environmental pollutants but would also prolong healthy life expectancy could be inserted into humans. Again, would it be permissible to let people continue suffering such damage when they could be protected against it? Would it in short be O.K. to let them suffer?

It is not normal for the human organism to be self-repairing in this way, this must be eugenic if anything is. But if available, its use would surely, like penicillin before it, be more than merely permissive.

Of course, there will be unclarity at the margins but at least this conception of disability captures and emphasises the central notion that a disability is disabling in some sense, that it is a harm to those who suffer, it, and that to knowingly disable another individual or leave them disabled when we could remove the disability is to harm that individual. ${ }^{5}$

This is not an exhaustive definition of disability but it is a way of thinking about it which avoids certain obvious pitfalls. First it does not define disability in terms of any conception or normalcy. Secondly it does not depend on post hoc ratification by the subject of the condition - it is not a prediction about how the subject of the condition will feel. This is important because we need an account of disability we can use for the potentially self-conscious; gametes, embryos, fetuses and neonates and for the temporarily unconscious, which does not wait upon subsequent ratification by the person concerned.

"In this sense the definition of disability is like that of "poverty".

${ }^{5}$ See my more detailed account of the relationship between harming and wronging in my Wonderwoman $\mathcal{E}$ Superman Oxford University Press, Oxford 1992 Chapter 4. 
With this account in mind we can extract the sting from at least one dimension of the charge that attempts to produce fine healthy children might be wrongful. Two related sorts of wrongfulness are often alleged here. One comes from some people and groups of people with disability or from their advocates. The second comes from those who are inclined to label such measures as attempts at eugenic control.

It is often said by those with disability or by their supporters ${ }^{6}$ that abortion for disability, or failure to keep disabled infants alive as long as possible, or even positive infanticide for disabled neonates, constitutes discrimination against the disabled as a group, that it is tantamount to devaluing them as persons, to devaluing them in some existential sense. Alison Davis identifies this view with utilitarianism and comments further that "(i)t would also justify using me as a donor bank for someone more physically perfect (I am confined to a wheelchair due to spina bifida) and, depending on our view of relative worth, it would justify using any of us as a donor if someone of the status of Einstein or Beethoven, or even Bob Geldof, needed one of our organs to survive". ${ }^{7}$ This is a possible version of utilitarianism of course, but not I believe one espoused by anyone today. On the view assumed here and which I have defended in detail elsewhere, ${ }^{8}$ all persons share the same moral status whether disabled or not. To decide not to keep a disabled neonate alive no more constitutes an attack on the disabled than does curing disability. To set the badly broken legs of an unconscious casualty who cannot consent does not constitute an attack on those confined to wheelchairs. To prefer to remove disability where we can is not to prefer non-disabled individuals as persons. To reiterate, if a pregnant mother can take steps to cure a disability affecting her fetus she should certainly do so, for to fail to do so is to deliberately handicap her child. She is not saying that she prefers those without disability as persons when she says she would prefer not to have a disabled child.

The same is analogously true of charges of eugenics in related circumstances. The wrong of practising eugenics is that it involves the assumption that "those who are genetically weak should be discouraged from reproducing" or are less morally important than other persons and that compulsory measures to prevent them reproducing might be defensible.

${ }^{6}$ Who should of course include us all.

${ }^{7}$ Davis 1988. p. 150.

${ }^{8}$ See my The Value of Life, Routledge, London 1985 \& 1990 Ch.1 and my "Not all babies should be kept alive as long as possible" in Raanan Gillon and Anne Lloyd Eds. Principles of Health Care Ethics, John Wiley \& Sons, Chichester, in press, publication 1993. 
It is not that the genetically weak should be discouraged from reproducing but that everyone should be discouraged from reproducing children who will be significantly harmed by their genetic constitution. ${ }^{9}$

Indeed, gene therapy offers the prospect of enabling the genetically weak to reproduce and give birth to the genetically strong. It is to this prospect and to possible objections to it that we must now turn.

In so far as gene therapy might be used to delete specific genetic disorders in individuals or repair damage that had occurred genetically or in any other way it seems straightforwardly analogous to any other sort of therapy and to fail to use it would be deliberately to harm those individuals whom its use would protect.

It might thus, as we have just noted, enable individuals with genetic defects to be sure of having healthy rather than harmed children and thus liberate them from the terrible dilemma of whether or not to risk having children with genetic defects.

Suppose now that it becomes possible to use gene therapy to introduce into the human genome genes coding for antibodies to major infections like AIDS, Hepatitis B, Malaria and others, or coding for repair enzymes which could correct the most frequently occurring defects caused by radiation damage, or which could retard the ageing process and so lead to greater healthy longevity, or which might remove predispositions to heart disease, or which would destroy carcinogens or maybe permit human beings to tolerate other environmental pollutants? ${ }^{10}$

I have called individuals who might have these protections built into their germ line a "new breed". ${ }^{11}$ It might be possible to use somatic cell therapy to make the same changes. I am not here intersted in the alleged moral differences between germ line and somatic line therapy, though elsewhere I have argued strongly that there is no morally relevant difference. ${ }^{12}$ The question we must address is whether it would be wrong to fail to protect individuals in ways like these which would effectively enhance their function rather than cure dysfunction, which would constitute improvements in human individuals or indeed to the human genome, rather than simple (though complex in another sense and sophisticated) repairs? I am assuming

9 I use the term "weak" here to echo Chadwick's use of the term. I take "genetically weak" to refer to those possessing a debilitating genetic condition or those who will inevitably pass on such a condition. All of us almost certainly carry some genetic abnormalities and are not thereby rendered "weak".

${ }^{10}$ Here I borrow freely from my Wonderwoman $\mathcal{E}$ Superman: The Ethics of Human Biotechnology Oxford University Press 1992. Chapter 9, where I discuss all these issues in greater depth than is possible here.

${ }^{11}$ Ibid.

${ }^{12}$ Ibid Chapter 8. 
of course that the technique is tried, tested and safe.

To answer this question we need to know whether to fail to protect individuals whom we could protect in this way would constitute a harm to them. ${ }^{13}$ The answer seems to be clearly that it would. If the gene therapy could enhance prospects for healthy longevity then just as today, someone who had a life expectancy of fifty years rather than one of seventy would be regarded as at a substantial disadvantage, so having one of only seventy when others were able to enjoy ninety or so would be analogously disadvantageous. However even if we concentrate on increased resistance, or reduced susceptibility, to disease there would still be palpable harms involved. True, to be vulnerable is not necessarily to suffer the harm to which one is vulnerable, although even this may constitute some degree of psychological damage. However the right analogy seems here to be drawn from aviation.

Suppose aircraft manufacturers could easily build in safety features which would render an aircraft immune to, or at least much less susceptible to, a wide range of aviation hazards. If they failed to do so we would regard them as culpable whether or not a particular aircraft did in fact succumb to any of these hazards in the course of its life. They would in short be like a parent who failed to protect her children from dangerous diseases via immunization or our imagined parent who fails to protect through gene therapy.

I hope enough has been said to make clear that where gene therapy will effect improvements to human beings or to human nature that provide protections from harm or the protection of life itself in the form of increases in life expectancy ('death postponing' is after all just 'life saving' redescribed) then call it what you will, eugenics or not, we ought to be in favour of it. There is in short no moral difference between attempts to cure dysfunction and attempts to enhance function where the enhancement protects life or health.

\section{WHAT SORTS OF ENHANCEMENT PROTECT HEALTH?}

I have drawn a distinction between attempts to protect life and health and other uses of gene therapy. I have done so mostly for the sake of brevity and to avoid the more contentious area of so-called cosmetic or frivolous uses of gene therapy. Equally and for analogous reasons I have here failed to distinguish between gene therapy on the germ line and gene therapy on the somatic line. I avoid contention here not out of distaste for combat but simply because to deploy

${ }^{13}$ For an elaboration on the importance of this distinction see my discussion of 'the wrong of wrongful life' in Wondenwoman $\mathcal{E}$ Superman Chapter 4. 
the arguments necessary to defend cosmetic uses of gene therapy would take up more space than I have available now. Elsewhere I have deployed these arguements. ${ }^{14}$ However, the distinction between preservation of life and health or normal medical uses and other uses of gene therapy is difficult to draw and it is worth here just illustrating this difficulty.

The British Governments' "Committee on the Ethics of Gene Therapy" in its report to Parliament attempted to draw this distinction. The report, known by the surname of its chairman as The Clothier Report suggested "in the current state of knowledge it would not be acceptable to attempt to change traits not associated with disease". ${ }^{15}$ This was an attempt to rule out so called cosmetic uses of gene therapy which would include attempts to manipulate intelligence. ${ }^{16}$

Imagine two groups of mentally handicapped or educationally impaired children. In one the disability is traceable to a specific disease state or injury, in the other it has no obvious cause. Suppose now that gene therapy offered the chance of improving the intelligence of children generally and those in both these groups in particular. Those who think that using gene therapy to improve intelligence is wrong because it is not a dimension of health care would have to think that neither group of children should be helped and those, like Clothier, who are marginally more enlightened would have to think that it might be ethical to help children in the first group but not those in the second. ${ }^{17}$

I must now turn to the question of whether or not gene therapy as a technique is specially morally problematic.

\section{WHAT'S WRONG WITH GENE THERAPY?}

Gene therapy may of course be scientifically problematic in a number of ways and in so far as these might make the procedure unsafe we would have some reason to be suspicious of it. However these problems are ethically uninteresting and I shall continue to assume that gene therapy is tried and tested from a scientific perspective. What else might be wrong with it?

One other ethical problem for gene therapy has been suggested

${ }^{14}$ Ibid. Chapter 7.

${ }^{15}$ Report of the Committee on the Ethics of Gene Therapy, presented to Parliament by Command of Her Majesty, January 1992. London HMSO para.4.22.

${ }^{16}$ In fact intelligence is unlikely to prove responsive to such manipulation because of its multifactorial nature.

17 There would be analogous problems about attempts to block the use of gene therapy to change things like physical stature and height since it might be used in the treatment of achondroplasia or other forms of dwarfism. 
and it deserves the small space left. Ruth Chadwick has given massive importance to the avoidance of doubt over ones genetic origins. Chadwick suggests that someone:

who discovers that her parents had an extra gene or genes added . . . may suffer from what today in the 'problem pages' is called an 'identity crisis' . . Part of this may be an uncertainty about her genetic history. We have stressed the importance of this knowledge, and pointed out that when one does not know where 50 per cent of one's genes come from, it can cause unhappiness. ${ }^{18}$

Chadwick then asks whether this problem can be avoided if only a small amount of genetic make-up is involved. Her answer is equivocal but on balance she seems to feel that "we must be cautious about producing a situation where children feel they do not really belong anywhere, because their genetic history is confused." 19 This sounds mild enough until we examine the cash value of phrases like "can cause unhappiness" or "be cautious" as Chadwick uses them.

In discussing the alleged unhappiness caused by ignorance of 50 per cent of one's genetic origin, Chadwick argued strongly that such unhappiness was so serious that "it seems wise to restrict artificial reproduction to methods that do not involve donation of genetic material. This rules out AID, egg donation, embryo donation and partial surrogacy". ${ }^{20}$

In elevating doubt about one's genetic origin to a cause of unhappiness so poignant that it would be better that a child who might experience it had never been born, Chadwick ignores entirely the (in fact false) truism that while motherhood is a fact paternity is always merely a hypothesis. It is a wise child indeed that knows her father and since such doubt might reasonably cloud the lives of a high proportion of the population of the world, we have reason to be sceptical that its effects are so terrible that people should be prevented from reproducing except where such doubt can be ruled out.

The effect of Chadwick's conclusion is to deny gay couples and single people the possibility of reproducing. Chadwick denies this suggesting "they are not being denied the opportunity to have children. If they are prepared to take the necessary steps ('the primitive sign of wanting is trying to get') their desire to beget can be satisfied." What are we to make of this? It seems almost self-consciously mischievous. In the first place gay couples and single women resorting

${ }^{18}$ Ruth Chadwick Ethics, Reproduction and Genetic Control, Routledge, London, 1987. page 126 .

${ }^{19}$ Ibid. page 127.

${ }^{20}$ Ibid. page 39 . 
to what must, ex hypothesi, be distasteful sex with third parties merely for procreational purposes, are unlikely to preserve the identity of their sexual partners for the benefit of their offspring's alleged future peace of mind. If this is right then doubt over genetic origin will not be removed. Since Chadwick is explicitly addressing public policy issues she should in consistency advocate legislation against such a course of action rather than recommend it.

But surely, if we are to comtemplate legislating against practices which give rise to doubt about genetic origins we would need hard evidence not only that such practices harm the resulting children but that the harm is of such high order that not only would it have been better that such children had never been born but also better that those who want such children should suffer the unhappiness consequent on a denial of their chance to have children using donated genetic material?

Where such harm is not only unavoidable but is an inherent part of sexual reproduction and must affect to some degree or other a high percentage of all births, it is surely at best unkind to use the fear of it as an excuse for discriminating against already persecuted minorities in the provision of reproductive services.

Where, as in the case of gene therapy, such donated ${ }^{21}$ material also protects life and health or improves the human condition we have an added reason to welcome it.

Centre for Social Ethics and Policy

University of Manchester

\section{NOTES}

This paper was presented at the Inaugural Congress of the International Association of Bioethics, Amsterdam, The Netherlands, 5-7th October 1992. I am grateful to the audience at that meeting and particularly to Dan Brock, Norman Daniels, Raanan Gillon, Douglas Maclean and Maurice de Wachter for helpful comments.

${ }^{21}$ I use the term 'donated' here but I do not mean to rule out commerce in such genetic material. See $M y$ Wonderwoman \& Superman. Chapter 6. 